\title{
AIR-COUPLED IMPACT-ECHO SCANNER: FAST AND CONTACTLESS NONDESTRUCTIVE TESTING OF CONCRETE PAVEMENTS
}

\author{
Robin Groschup ${ }^{1}$ and Rudolph N. Kraus ${ }^{2}$ \\ ${ }^{1}$ - Ingenieurbüro Schiessl, Gehlen, Sodeikat, Munich, Germany. Former Group \\ Leader of the Chair of Non-destructive Testing, Centre for Building Materials, \\ Technical University of Munich, Baumbachstrasse 7, 81245, Munich, Germany, \\ Email: robin.groschup@tum.de \\ ${ }^{2}$ Chair of Nondestructive Testing, Centre for Building Materials, Technical \\ University of Munich, Baumbachstrasse 7, 81245, Munich, Germany, Email: \\ rudolph.kraus@tum.de
}

\begin{abstract}
The remaining useful life of concrete highway pavements is adversely affected by horizontal cracks or delaminations occurring within the pavement. This damage is not visible from the surface but poses an extreme danger to traffic if a spontaneous and massive expansion of these defects occurs due to variations in temperature. To prevent serious traffic restrictions or even accidents, a method to efficiently and quickly locate and evaluate defects is required so repairs can be planned and completed in a timely manner.

The air-coupled impact-echo scanner presented in this paper was developed at the Technical University of Munich. This new scanner fulfills the major challenges for a non-destructive pavement testing system to be able to examine long stretches of pavements with a high acquisition speed and high detection probability. An optimized sensing concept in combination with a multiple excitation strategy was developed to minimize signal to noise ratio. The test equipment was tested and proven for routine use on highway pavements.
\end{abstract}

Keywords: Air-coupled impact-echo scanner, non-destructive pavement testing system, highway pavements.

\section{INTRODUCTION}

To obtain physical information on the state of structures that go beyond random testing, non-destructive test (NDT) methods are necessary which can be applied in a scanning mode that is time and cost efficient. Currently, the availability of scanning methods for NDT of concrete and reinforced concrete is mainly limited to methods with electrical, magnetic, or electromagnetic measurement principles (i.e. pulse burst 
radar or half-cell potential measurement with wheel electrodes). Scanning applications based on other measurement principles are often based on a stop-and-go operation and are therefore expensive since, for example, a scanner frame must be fabricated and installed, or sensors must be repeatedly removed and reconnected.

Internal cracking in concrete with small crack widths usually cannot be detected using electromagnetic methods due to limitations in resolution. However, such cracking can be detected by elastic waves interacting directly with the damage. Ultrasonic testing is based on elastic waves and is therefore very suitable for locating cracks, but it is very expensive to use in a scanning manner. Therefore, in practice, this method is mostly applied only to specific areas. Extrapolation of the local results to areas not directly covered by the measurement is usually not possible. The impact-echo method (Sansalone and Carino, 1986) (DGZfP-Merkblatt B11, 2011) also utilizes elastic waves (similar to ultrasonic testing), but due to the underlying physical principles, offers significant potential for the development of a test scanner to be used for continuous measurements from a mobile platform.

This paper describes the prototype test system developed at the Technical University of Munich (TUM) based on the impact-echo principle using air-coupled sensors (Groschup and Grosse, 2015) (Groschup and Grosse, 2016) (Zhu and Popovics, 2006) (Zhu and Popovics, 2007) along with typical applications. The primary objective of the test device was to detect horizontal cracks and delaminations in concrete pavements in a scanning mode. However, the device and the analysis method can also be applied to other structures and to detect other defects.

\section{IMPACT-ECHO MEASUREMENT TECHNOLOGY}

\section{Fundamentals of Impact-Echo}

Impact Echo (IE) can be explained as the metrological implementation of a "tap test." In the IE method, elastic waves are generated from a mechanical impact (e.g., impact by a hammer or impact of a steel ball) on the surface of a structural component to be inspected. The vibrations generated by these waves on the surface are measured, in the classical application of IE, by a sensor mounted near the impact. For evaluation and interpretation, these signals are then transformed into the frequency domain. The position of maximum frequency in the generated signal spectra can be used to infer structural properties such as plate thicknesses or defects. This makes it possible to assign IE to the group of methods of Local Acoustic Resonance Spectroscopy (LARS) (Grosse, Jüngert and Jatzlau, 2018).

In plate structures, of particular relevance is the formation of a so-called "thickness mode resonance." Early explanations of this measurement effect were based on multireflected P-waves (compression waves) between top and bottom surfaces of the plate. The correct physical explanation is from the theory of Lamb waves, where the 
thickness resonance can be described as the frequency of a symmetrical plate wave (Gibson and Popovics, 2005).

When detecting damage in plate structures, in particular when horizontal cracks and delaminations (including voids) are present, another measurement effect is caused by the impact: Flexural oscillations (bending modes of vibration) can be induced in local areas (Oh, Popovics and Sim, 2013). For engineering-relevant dimensions of slab thicknesses and defects, these vibrations typically have lower frequencies than the thickness mode resonance (

Fig. 1). The described frequency effects of IE measurements can thus be used for damage detection:

If the measured data has a clearly discernible maximum frequency, correlating to the thickness resonance, it can be assumed that the plate structure is undamaged. When lower frequencies dominate the measurement signal, flexural vibrations due to defects (delaminated areas, horizontal cracks, or voids) may be present.

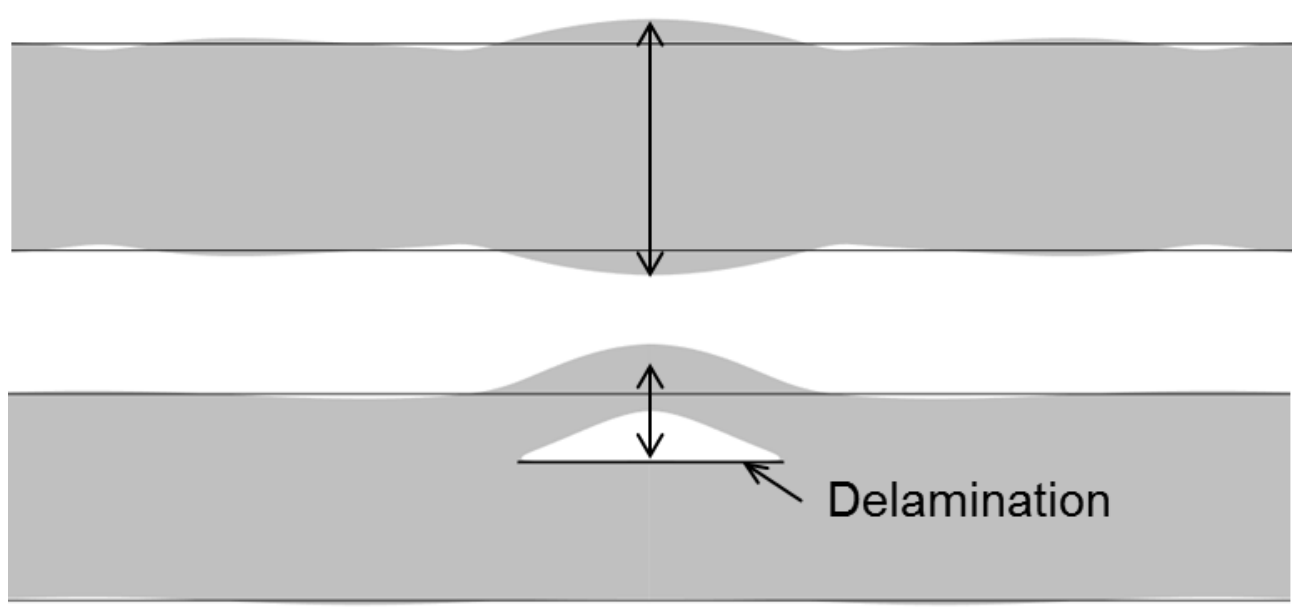

Fig. 1. Top: Thickness mode resonance in undamaged structure after impact. Bottom: Bending mode of vibration at a delaminated area after impact.

For typical IE frequencies, there is a distinct technical advantage: the relevant frequencies are in the audible range and the energies generated from typical impactor masses cause a measurable structure-borne sound reflection into the air. As a result, the signals relevant for IE can also be recorded with microphones that do not require direct contact with the surface. When recording airborne sound interference due to background noise and noise from the apparatus itself occurs, however through an optimized sensor design (Groschup and Grosse, 2015), it is still possible to record the relevant signals with a sufficient SNR (signal-to-noise ratio), even when operating under typical highway conditions.

Numerical simulations proved to be extremely useful when designing the sensor elements and establishing the measurement effects expected for delaminations. By correlating the elastic wave 
propagation in concrete with the airborne sound propagation, the sound field that is radiated can be illustrated and measured (

Fig. 2).

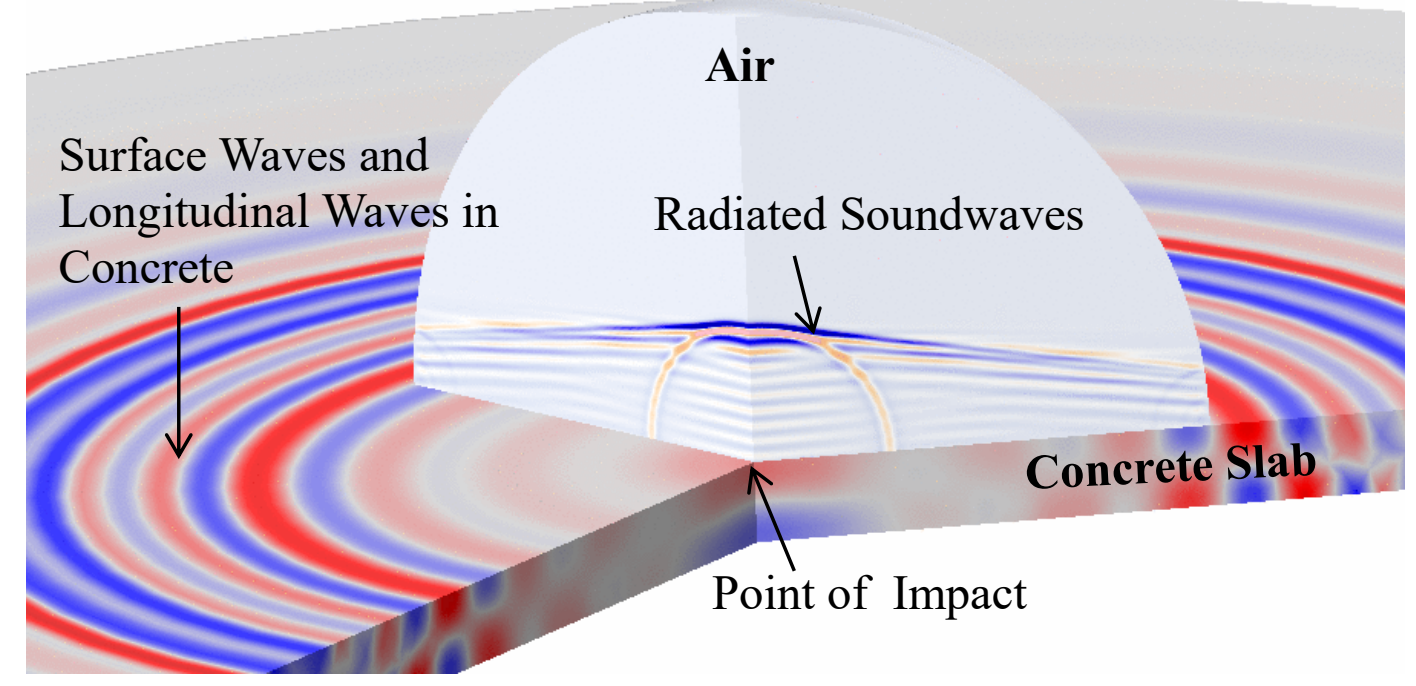

Fig. 2. Simulation of wave propagation in concrete and sound radiation in air using a radially symmetric material model 


\section{Prototype Scanner}

The prototype of the modular scanner system developed at the Technical University of Munich is shown in

Fig. 3. The scanner uses specially configured microphone arrays and automated impact encoders developed for the measurements, which excite rapidly repeating and reproducible individual signals. In its current stage of development, the modular scanner can test up to three parallel tracks simultaneously.

A displacement sensor allows position-controlled programming of impact excitation and measurement intervals. The RTK GPS system used in the scanner provides sufficiently accurate positioning, even over long measuring distances. Additional optional sensors, such as cameras and laser sensors, allow the user to locate joints and provides information about the general condition of the surface. In the positionreferenced camera images, material variations (such as repairs) can be identified and compared with the test data.

The test speed (and thus the measuring grid) must be matched to the expected size of defects. In addition, the speed is limited by the maximum possible impact frequency. In the current development stage of the scanner can be used at a pace of walking. One of the goals of ongoing development work is to increase the test speed.

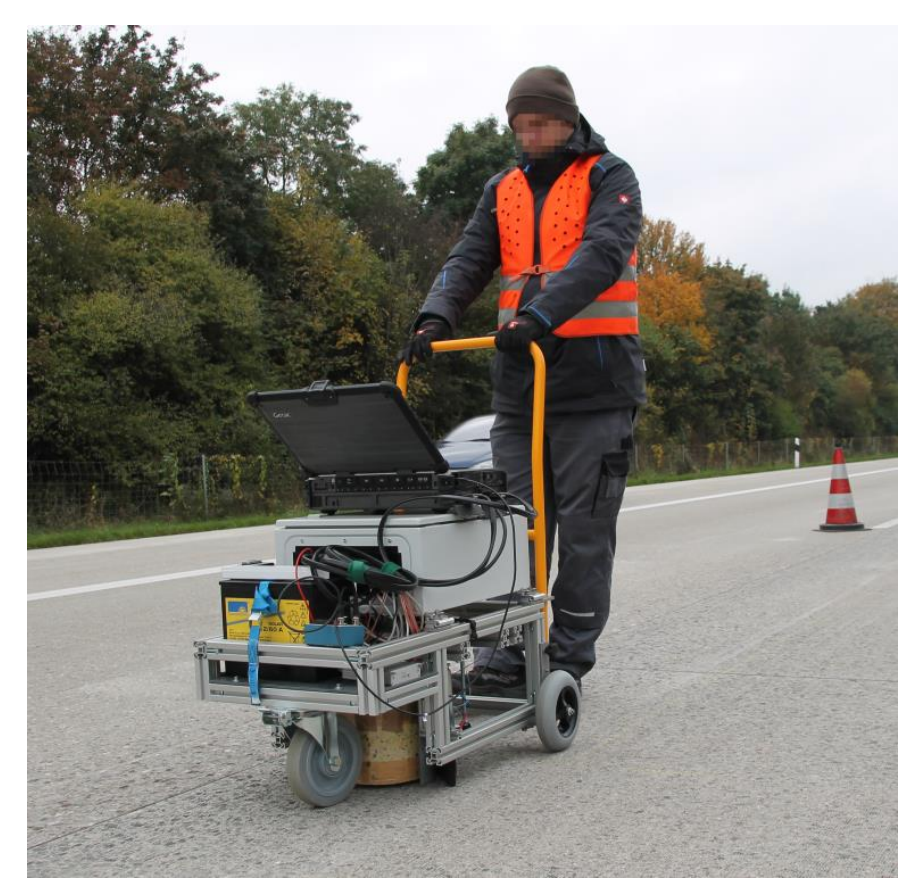

Fig. 3. Prototype of the impact-echo scanner used on a concrete pavement slab. 


\section{APPLICATIONS}

\section{Cracking near Concrete Pavement Joints}

A typical form of distress found in concrete pavements is horizontal cracking at joints. Such cracking can have various causes, for example, alkali-silica reaction (ASR) or thermal and mechanical stress. The prototype scanner developed at the TUM could be used on pavements of different constructions when such horizontal cracking is
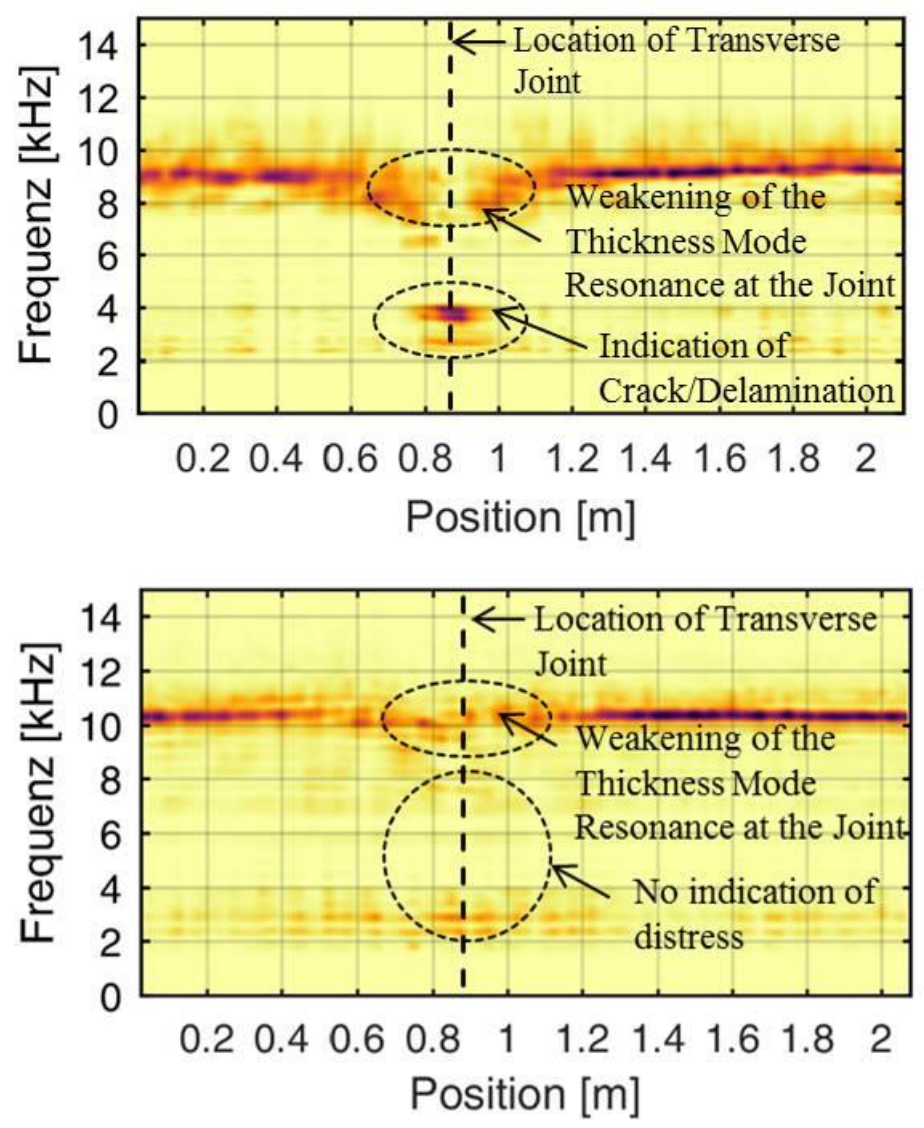

suspected at joints.

Fig. 4 (top) shows the test data of a measurement across a transverse joint. The data shows the thickness mode resonance at approx. $9 \mathrm{kHz}$ which is interrupted by lowfrequency results in the area near the joint. The low-frequency results can be interpreted as an indication of a flexural vibration mode of a delaminated area. 

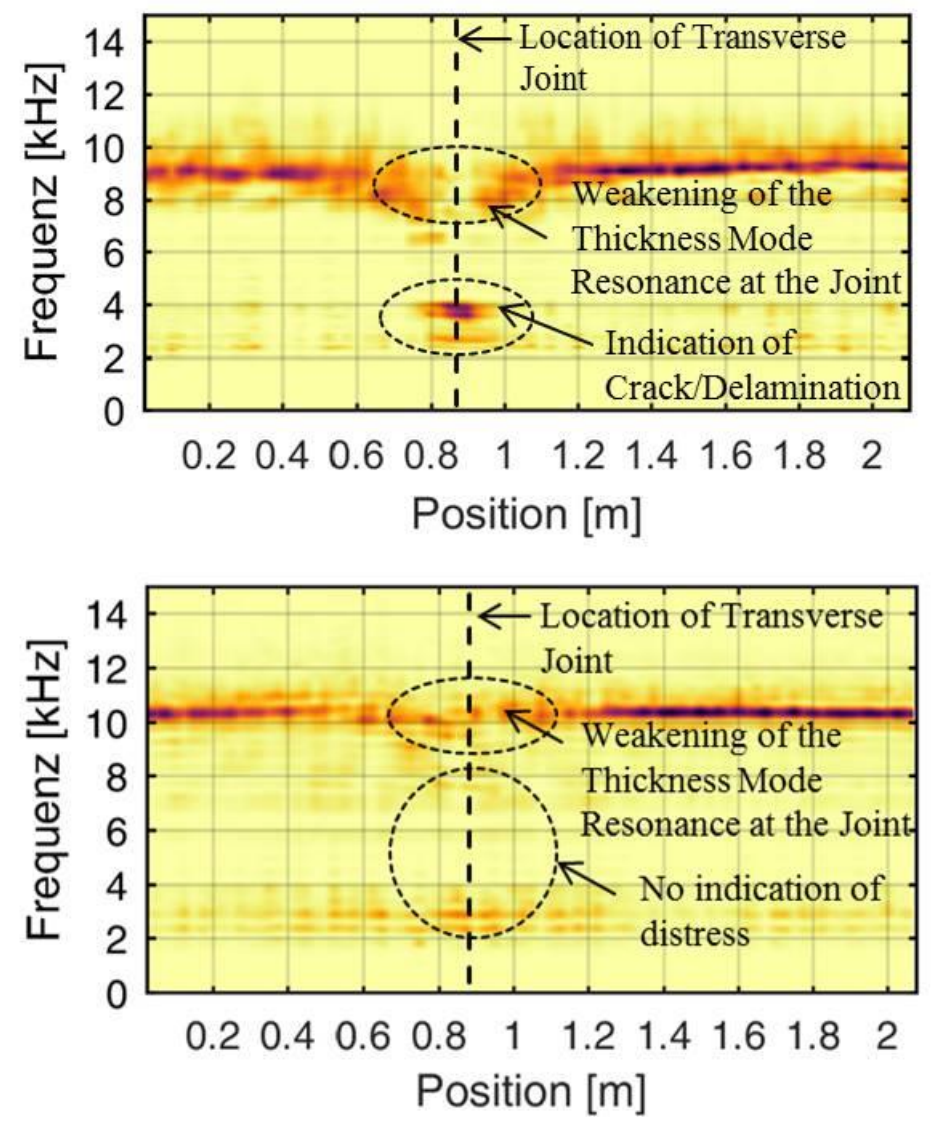

Fig. 4 (bottom) shows test data from a measurement across a transverse joint without cracking. Here, the thickness resonant frequency is also found in the area near the joint. There are no lower frequency results visible near the joint.

These findings could be confirmed with ultrasonic testing at these locations as well as through drilled cores. (

Fig. 5). 

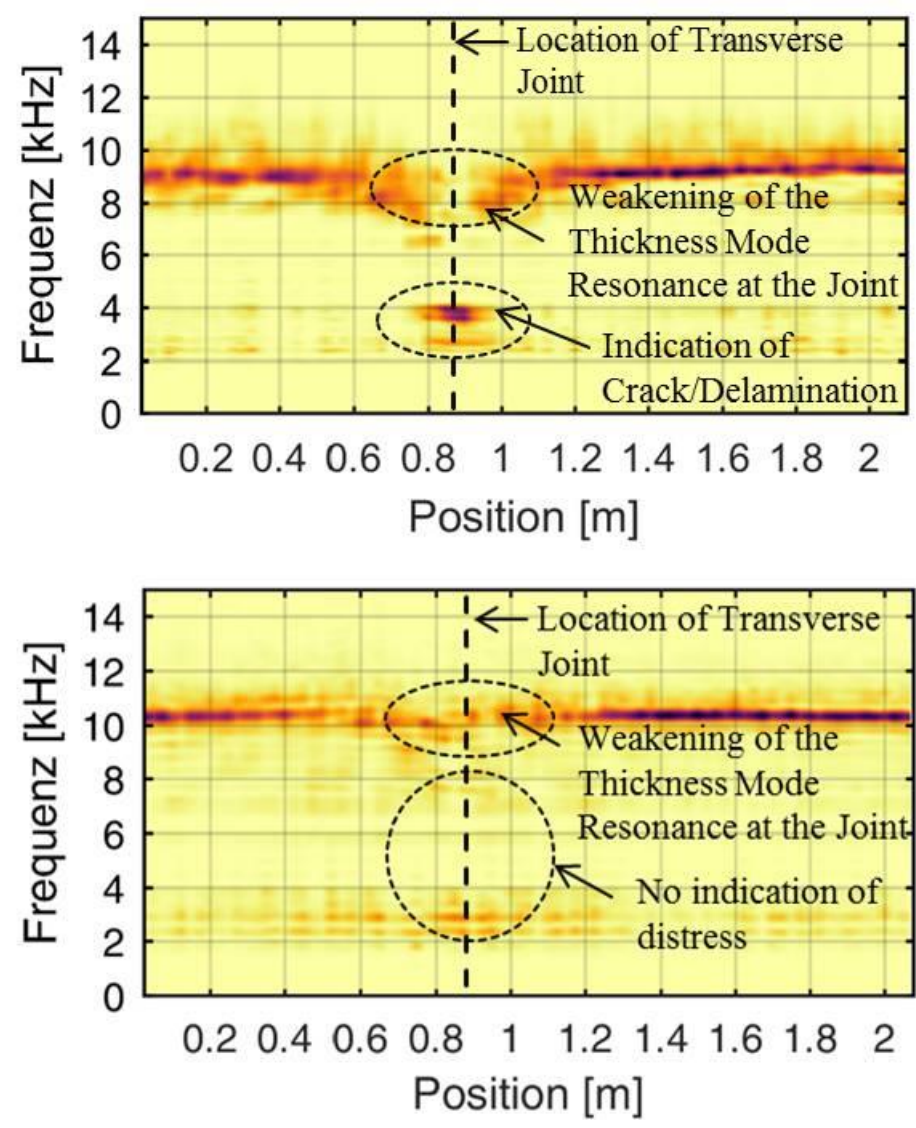

Fig. 4. Test results on concrete pavement slab with approx. $20 \mathrm{~cm}$ thickness. Test frequency is shown as a function of the position. The dashed line marks the position of the transverse joint. Top: Measurement at a joint with horizontal cracking, Bottom: Measurement at an undamaged joint.

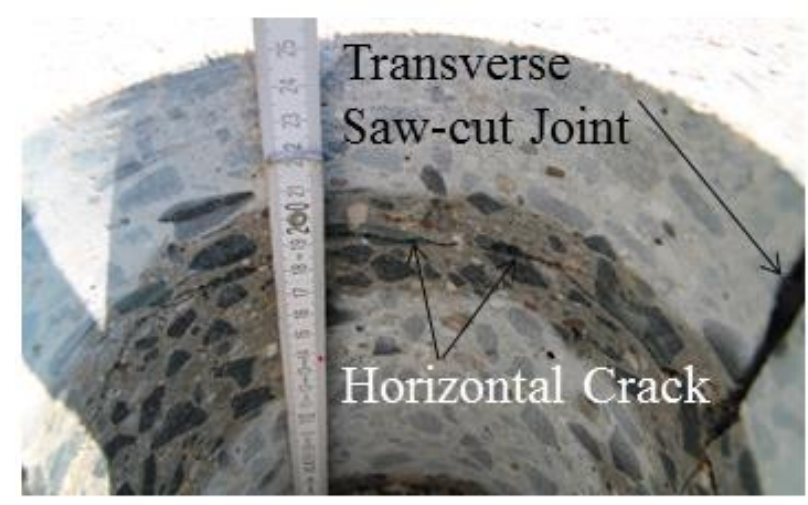


Fig. 5. Interior wall of a core hole at a sawed contraction joint with horizontal cracking starting from the bottom of the sawcut. The test measurement at this joint

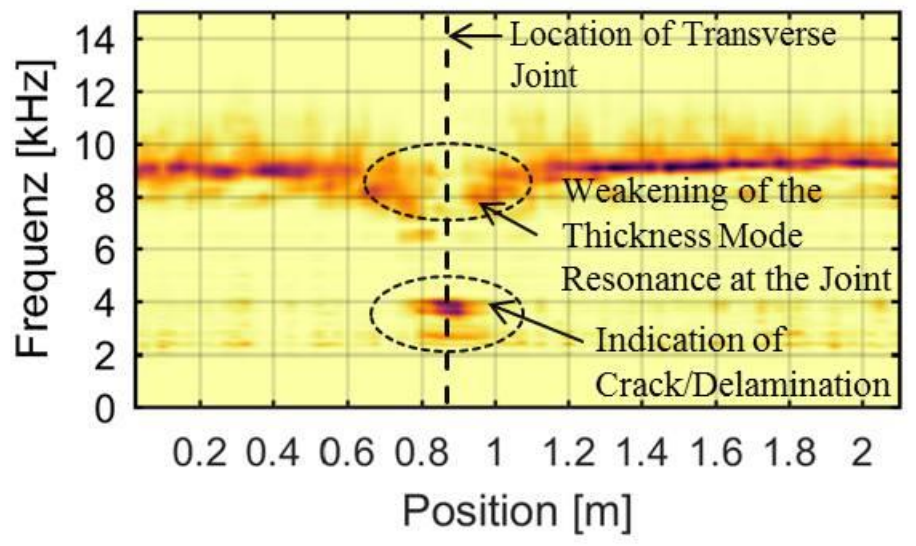

before coring is shown in

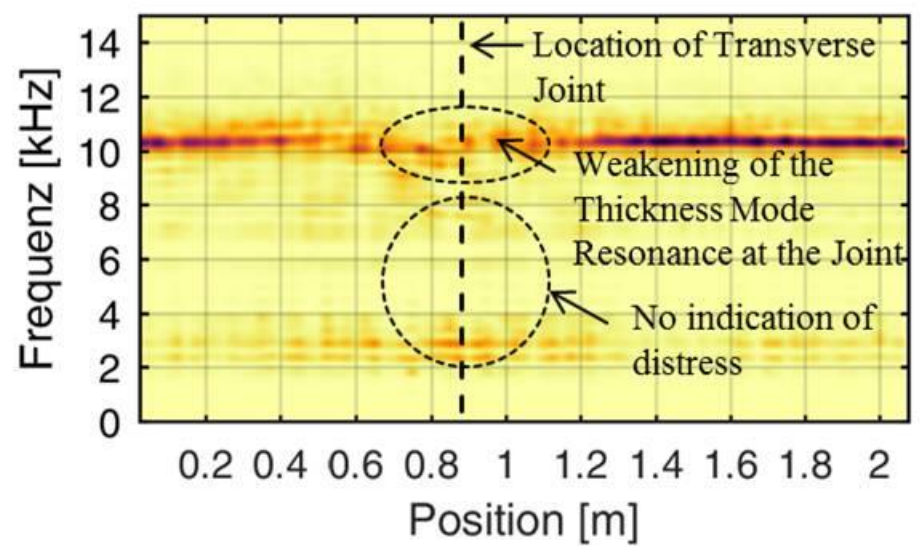

Fig. 4, Top.

\section{Delamination in a Bridge Deck}

In addition to the case shown above where the damage is concentrated at joint locations, there are of course applications in which a continuous acquisition of measurement data is necessary. For example, this is the case for bridge structures where the goal is to locate delamination in the deck.

As part of the pilot project for the IE scanner, continuous line scans were conducted on a bridge deck structure with a total of approx. $7 \mathrm{~km}$ measured length. The results of the tests could be evaluated automatically. Results showing delaminations (i.e., high amplitude values at a frequency lower than that of thickness mode resonance) were segmented and transferred to a CAD-based damage database. This allowed for a comparison with conventionally obtained information on the condition of the structure ( 
IE - Frequency Response

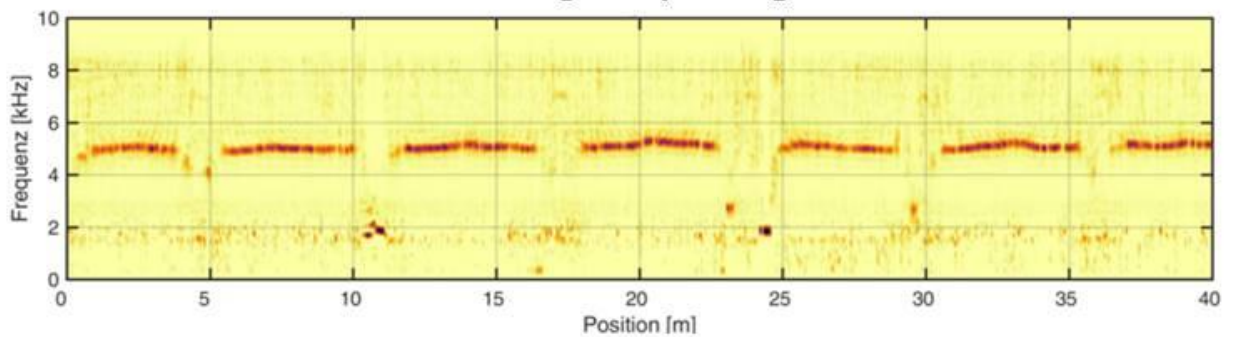

Automatic Segmented Location of Defects

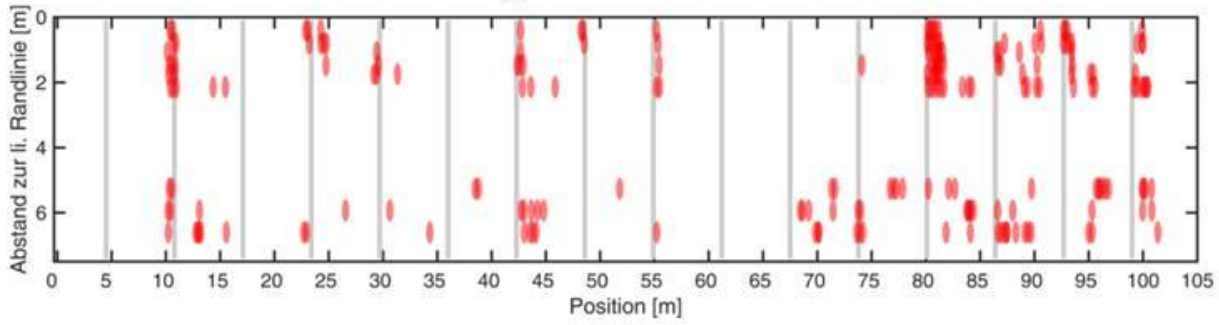

Import in CAD-Database

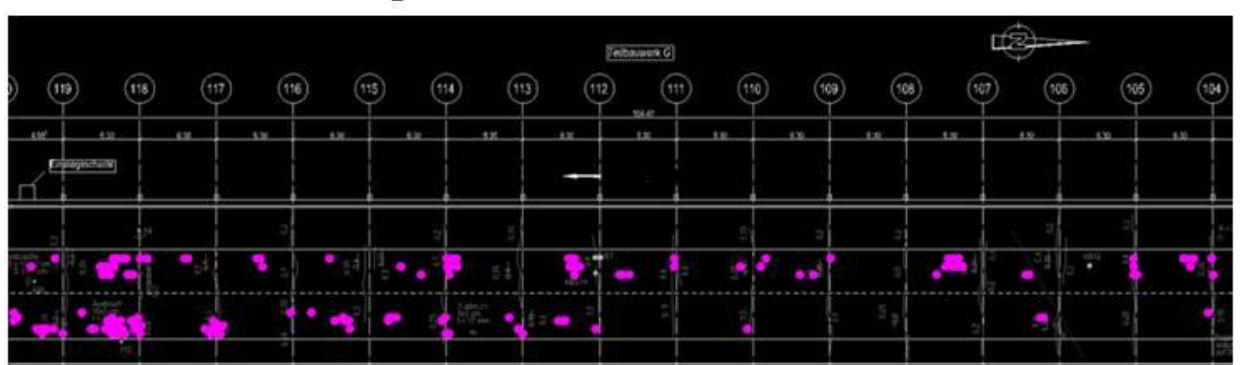

Fig. 6). The building owner can thus use the test results with the goal of planning maintenance and repairs. 


\section{IE - Frequency Response}

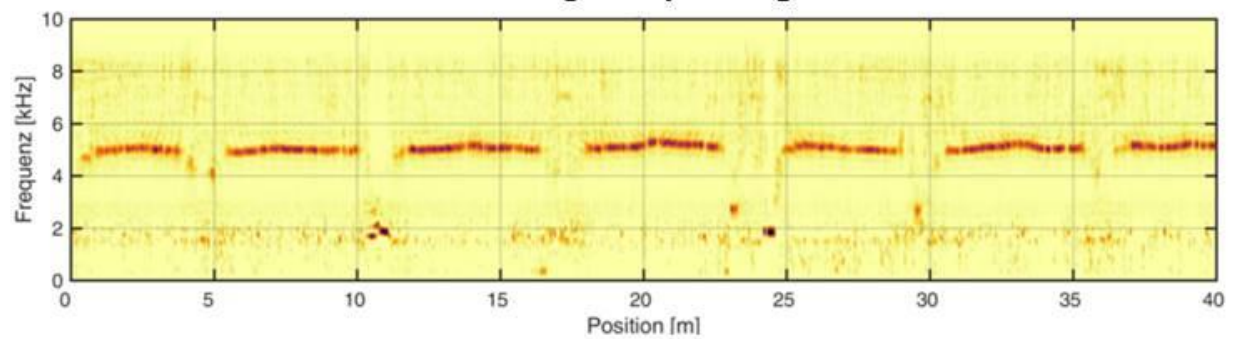

Automatic Segmented Location of Defects

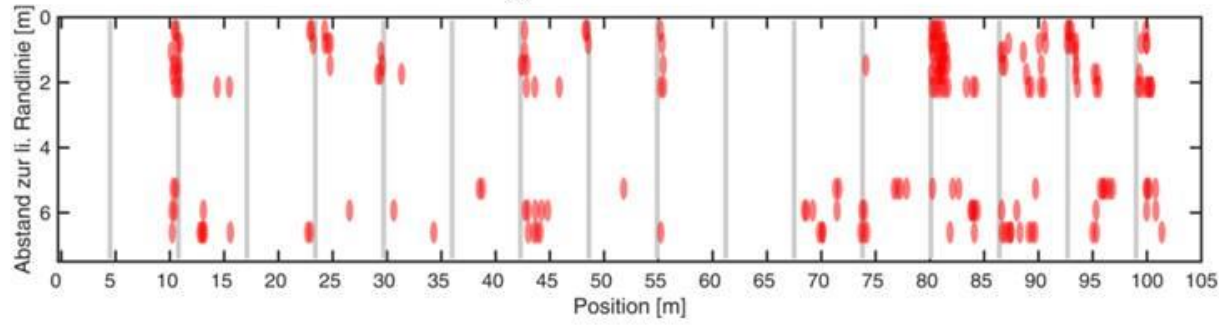

Import in CAD-Database
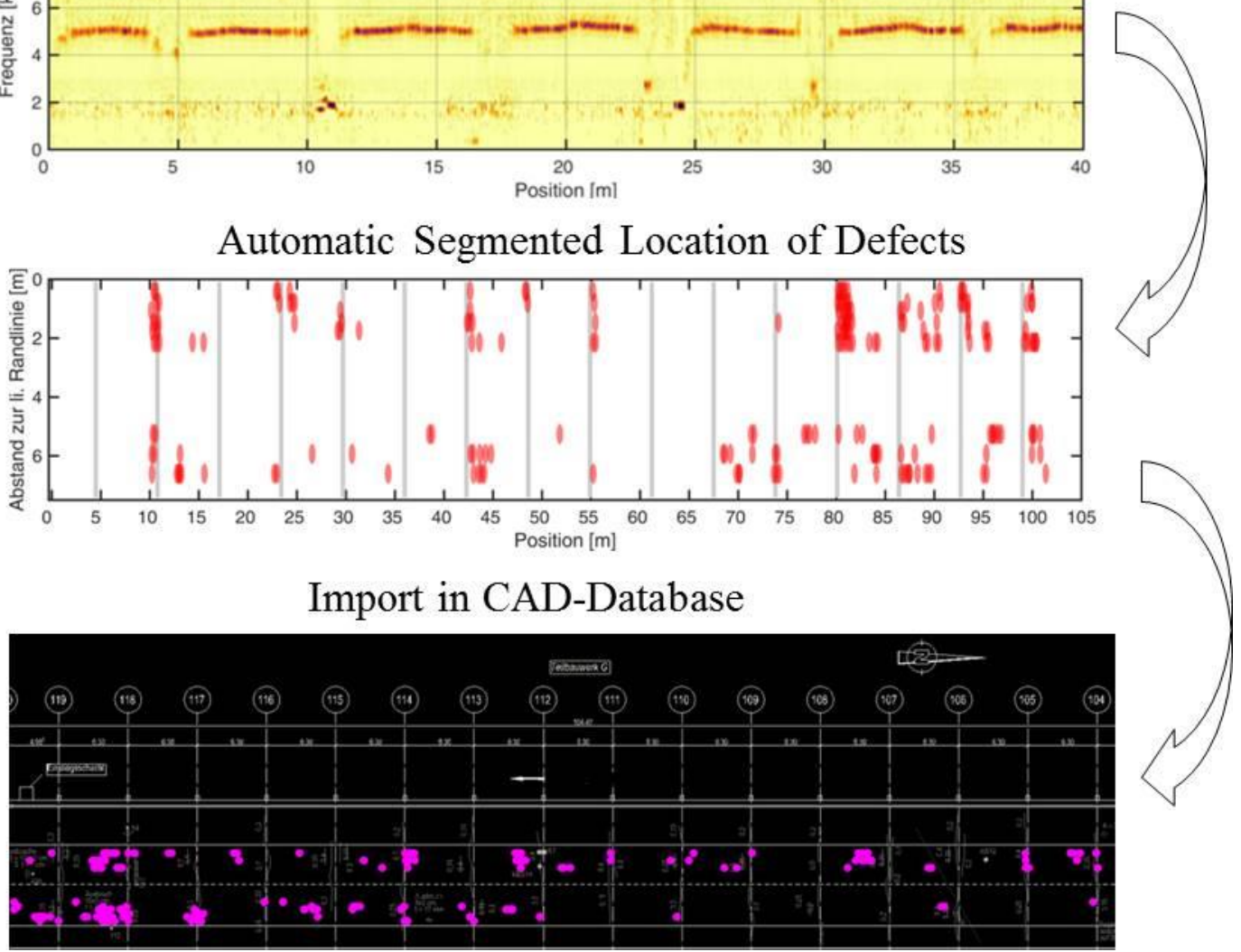

Fig. 6. Example of the automated evaluation from impact-echo data to CAD-based damage database.

\section{SUMMARY}

A mobile NDT scanner has been developed here at the TUM based on impact echo technology, used for scanning concrete pavement structures in the field, which can identify small-scale cracking and delamination defects. Thus, it represents a significant improvement of existing testing technology. Up to this point, interior cracking not visible from the surface was primarily identified using ultrasound technology and was extremely time intensive. When using the IE scanner, meaningful information on the condition of the structure can be obtained in a practical timeframe.

Due to the physical measurement principle, certain restrictions must be observed when using the scanner. If at the same location, several horizontal cracks are present at different depths, only the uppermost crack plane will be identified by the scanner. Therefore the method cannot provide information whether there are additional cracks present under a detected crack. 
In the current stage of development the IE scanner can be operated at walking pace. The maximum possible measuring speed must be adapted to the size of the defect to be detected. An increase in the scanning speed and the determination of the probability of detection (POD) are the subject of current research and development activities.

The air-coupled IE measurement technology could also be applied to other types of structures for clarifying structural properties. For example, it is conceivable that the IE Scanner could be used for the detection of horizontal cracking and delamination in asphalt pavements. For this purpose, the frequency range of the excitation would have to be adapted by above all, a modification of the mass of the impactor. The determination of material properties (e.g. dynamic modulus of elasticity) is also possible with impact-echo based testing.

In addition, the IE scanner could also be used to detect delamination due to corrosion (in bridge decks, parking decks, underground parking garages), thickness measurement (e.g. floor slabs, tunnel liners) and in quality assurance of concrete structures where material composites or backfills must be checked (e.g. segmental construction of tunnels), possible. Further development work and an adaptation to these special test situations also make economic sense, since for many applications no scanning, nondestructive testing methods are available.

\section{ACKNOWLEDGEMENTS}

We acknowledge the support of the German Federal Highway Research Institute (Bundesanstalt für Straßenwesen). This presented work is conducted on behalf of the Federal Ministry of Transport and Digital Infrastructure, under grant No. FE-Nr. 08.0238/2015/CRB. The authors are solely responsible for the content.

We also thank the Federal Highway Research experts of the advisory committee for the useful suggestions.

We would also like to thank the Lower Saxony State Authority for Road Construction and Traffic and the engineering office of Inros Lacker for permission to present test results from a bridge deck. In addition, we express our gratitude to the Center for Building Materials and Materials Testing (cbm) of the Technical University of Munich for the manifold support and, in particular, to Mr. Sebastian Münchmeyer for his technical expertise that made the IE scanner a reality.

\section{REFERENCES}

DGZfP-Merkblatt B11 (2011): Merklatt über die Anwendung des Impakt-EchoVerfahrens zur Zerstörungsfreien Prüfung von Betonbauteilen; Ausgabe 201104. Berlin: Deutsche Gesellschaft für Zerstörungsfreie Prüfung (DGZfP).

Gibson, A. und Popovics, J.S. (2005). Lamb wave basis for impact-echo method analysis. Journal of Engineering Mechanics-Asce. 131(4), 438-443. 
Groschup, R. und Grosse, C.U. (2015). Enhancing Air-Coupled Impact-Echo with Microphone Arrays. Tagungsband Proceedings of the 2015 International Symposium on Non-Destructive Testing in Civil Engineering, NDT-CE. Berlin.

Groschup, R. und Grosse, C.U. (2015). MEMS Microphone Array Sensor for AirCoupled Impact-Echo. Sensors. 15(7), 14932-14945.

Groschup, R. und Grosse, C.U. (2016). Mikrofon-Array-Technik für scannendes Impakt-Echo-System - ein neuer messtechnischer Ansatz zur schnellen automatisierten Inspektion von Betonbauteilen. Ernst \& Sohn Special 2016 Messtechnik im Bauwesen. 49-54.

Grosse, C.U., Jüngert, A. und Jatzlau, P. (2018). Local Acoustic Resonance Spectroscopy. In Handbook of Advanced Non-Destructive Evaluation (N. Ida and N. Meyendorff Hrsg.). Heidelberg: Springer.

Oh, T., Popovics, J.S. und Sim, S.H. (2013). Analysis of vibration for regions above rectangular delamination defects in solids. Journal of Sound and Vibration. 332(7), 1766-1776.

Sansalone, M.J. und Carino, N.J. (1986). Impact-echo: A method for flaw detection in concrete using transient stress waves. National Bureau of Standards. Rep. No. NBSIR, 86-3452.

Zhu, J.Y. und Popovics, J.S. (2006). Air-coupled impact-echo method for NDT of concrete. Review of Progress in Quantitative Nondestructive Evaluation, Vols $25 A$ and 25B. 820, 1351-1357.

Zhu, J.Y. und Popovics, J.S. (2007). Imaging concrete structures using air-coupled impact-echo. Journal of Engineering Mechanics-ASCE. 133(6), 628-640. 